\title{
Key Factors for Consortial Success: Realizing a Shared Vision for Interlibrary Loan in a Consortium of Canadian Libraries
}

\section{Sue McGillivray}

Ontario Council of University Libraries

\section{Amy Greenberg}

Ontario Council of University Libraries

\section{Lucina Fraser}

Ryerson University

\section{Ophelia Cheung}

Ryerson University

McGillivray, S., Greenberg, A., Fraser, L., \& Cheung, O. (2009). Key factors for consortial success: Realizing a shared vision for interlibrary loan in a consortium of Canadian libraries. Interlending \& Document Supply, 37(1), 11-19.

$\underline{\text { doi: } 10.1108 / 02641610910938578}$

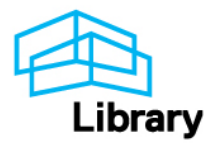




\title{
Key factors for consortial success: realizing a shared vision for interlibrary loan in a consortium of Canadian libraries
}

\author{
Sue McGillivray and Amy Greenberg \\ Ontario Council of University Libraries, Robarts Library, University of Toronto, Toronto, \\ Canada \\ Lucina Fraser and Ophelia Cheung \\ Ryerson University Library, Ryerson University, Toronto, Canada
}

\section{Acknowledgements}

This is a revised and updated paper originally presented at the 10th Interlending and Document Supply conference in Singapore, October 29-31, 2007. The Conference was sponsored by IFLA, whose cooperation and agreement to publish are gratefully acknowledged.Received: 26 July 2008Accepted: 4 September 2008

\begin{abstract}
Purpose - The purpose of this paper is to identify the factors associated with the successful implementation of a shared interlibrary loan (ILL) system by the Ontario Council of University Libraries (OCUL), a consortium of 20 Ontario universities.

Design/methodology/approach - The paper is a descriptive review of the approaches taken in the consortial implementation of OCLC's VDX software. The paper elaborates on the buildingblocks and barriers to success as they were experienced, first by participants in OCUL's centralized implementation activities, and second at the local level by staff at Ryerson University Library, a member institution. Now end users can simultaneously search world-wide catalogues, submit and track progress of requests, and receive materials rapidly. System functionality includes auto-mediated interlibrary loans (direct requesting); use of link-resolver software to transfer citation information from borrowing library catalogues to ILL request forms; and ISO peer-to-peer messaging.
\end{abstract}

Findings - Post-implementation analysis reveals several key factors that contributed to the project's success. These include: planning, leadership, financial support, technical support, cooperation, staff commitment, communication, staff-and end-user centered focus, training and evaluation.

Practical implications - This may have broad application for similar complex projects.

Originality/value - The OCUL VDX implementation has achieved the originally expected economies of scale, service performance improvements and reduction in localized maintenance and system support. However, there have also been several unforeseen benefits such as the 
formulation and standardization of the OCUL ILL policies, and the development of Canada-wide consortial reciprocal agreements. At the operational level, staff have had to adjust their management styles and develop confidence not only in their individual skills but also in cooperative thinking, reliance on centralized support, and in the overall system. Throughout the project the objectives have been clearly identified, and, for the most part, enthusiastically adopted, by consortium members. Recognizing that ILL is a service that is in transition, staff now look at business transformation and ways to identify, share and adopt best working practices.

\section{RACER and the OCUL Consortium}

The province-wide implementation of VDX interlibrary loan (ILL) software was one of the most ambitious projects (Cheung and Patrick, 2004) undertaken by the Ontario Council of University Libraries (OCUL) (Figure 1) to date. OCUL's membership comprises twenty Ontario universities. Working within a consortium model these libraries cooperate to enhance information services through resource sharing, collective purchasing, document delivery, collaboration on a digital repository, providing online access to Canadian statistical data and analysis tools and other activities. Each participating institution has access to a variety of resources and services, made available under the auspices of the Ontario Scholars Portal. This includes RACER, which stands for "Rapid Access to Collections by Electronic Requesting," the shared ILL system, that uses OCLC's (formerly Fretwell Downing's) VDX (Virtual Document eXchange) and ZPORTAL ILL software.

The implementation of RACER has been very complex. It required extensive cooperation and involved many levels of staff from all the OCUL participating institutions (OCUL members):

- Brock University;

- Carleton University;

- Lakehead University;

- Laurentian University;

- McMaster University;

- Nipissing University;

- Ontario College of Art \& Design;

- Ontario Institute of Technology;

- Queen's University;

- Royal Military College;

- Ryerson University;

- Trent University;

- University of Toronto;

- University of Guelph;

- University of Ottawa;

- University of Waterloo;

- University of Western Ontario;

- University of Windsor;

- Wilfrid Laurier University; and

- York University. 
After three years of envisioning, planning, and preparation, OCUL libraries started implementing in the summer of 2003. Implementation was phased across OCUL over a two and a half year period during which time the project has passed several milestones. In September 2005, the French version of the public interface was launched. In 2006-2007 several member-libraries moved from staff-mediated to auto-mediated interlibrary loans (direct requesting), which frees up time for staff to handle more difficult requests. More recently, libraries are using link-resolver software (see Appendix) to transfer citation information from borrowing library databases to ILL request forms. As of May 2008, the introduction of Jasper Reports allows local ILL Managers to generate ILL and Collection Development statistical reports on demand and in real-time or on a fixed schedule. The consortium continues to broaden its reach by implementing ISO peer-to-peer messaging beyond the OCUL network. As of July 2008, more than 2.6 million requests had been processed since 2003.

In the case of Ryerson University, participation in the OCUL interlibrary loan initiative has enabled the Ryerson Library to obtain a resource that could not be developed or maintained locally. Participating in the RACER project provides users with software, expanded services, gave staff opportunities for cooperation and networking, and easy access to resources beyond the Library's collection. Membership in the OCUL initiative allows Ryerson to both benefit from, and contribute to, the consortial vision.

Now that the OCUL ILL project has entered a maintenance and expansion phase, a look at some of the elements that have contributed to a successful implementation is worthwhile. Several key factors such as planning, support, and cooperation have helped the implementation teams avoid and address pitfalls that can often hinder consortial activities and information technology (IT) projects.

\section{Key factor - planning}

Key factors were: shared purpose, consensus on approach, development of consortial policies, flexibility

\section{Shared purpose and consensus on approach}

One of the key components of successful projects is having a strong central element or common interest (Best's Review, 2006). OCUL's purchase of new ILL software came out of a common need to replace existing ILL systems. It was recognized that the AVISO system, being used by most universities, was fast approaching the end of its lifecycle. It had limited vendor support with no plans for further development. Further, the libraries recognized that co-operative investigation and purchasing a shared system would:

- eliminate the need for 20 concurrent and independent assessment and implementation processes;

- leverage the buying power and resources of the consortium; and

- ultimately better facilitate ILL across the province. 
In March 2000 the OCUL Library Directors unanimously agreed to the recommendation to implement a centralized OCUL-wide VDX system. They also approved the creation of the OCUL ILL Task Group to make recommendations on how best to move forward with the implementation of the new interlibrary loan management system. This advisory group was made up of ILL and technical services people from across a representative sample of OCUL's member libraries. A consortial license was negotiated with Fretwell Downing and the OCUL ILL Task Group began setting targets, surveying members, analyzing system requirements, and communicating with members. A phase-in approach was adopted in response to the various needs and concerns expressed by institutions. Initiating the project within a task force framework created an early foundation of, not only shared purpose, but also a mechanism for arriving at consensus on the implementation approach, goals and desired final outcomes.

\section{Development of consortial policies}

IT Executive Russ Finney, in writing on successful team management, has said: "In order to achieve an integrated final product detailed guidelines are required to manage the participation of the many contributors to the developmental process” (Finney, 2003). During the early implementation phase, each OCUL member institution was required to assist the OCUL ILL Task Group and later the OCUL RACER Implementation Team by responding to a series of surveys. Data was compiled and analyzed to determine the best implementation options and establishing the overall customizations of the vendor's out-of-the box system. This also helped lay the groundwork for instituting project parameters, global settings and system-wide defaults. Ryerson Library participated by submitting detailed answers to the numerous surveys. The data evaluated included charts of local workflow at each of the potential sites; hardware and software; charging and invoicing information, statistical reports, resource-sharing policies, statements of common and individual goals and policies, and configuration information surveys. This data contributed to the definition of specifications for the product. This participatory approach not only resulted in the creation of the standards and guidelines for the initial developmental period but has remained in place and continues to underlie ongoing maintenance activities and development of new features and implementation of new functionality.

\section{Flexibility}

Any consortial project requires participants to be flexible and maintain a sense of co-operation. While all of the OCUL members are academic institutions and strongly dedicated to education, each library has its own agenda, shaped by its role within the local university and its commitment to university's overall goals and mission. As a result, there can be roadblocks brought about by the conflicting interests of stakeholders, and local commitments. Although all of the OCUL member ILL units share similar functions with commonalities in their activities, policies (e.g. charging end users) and workflows vary. Progress in the RACER project could not have been achieved without compromise. For example, all institutions needed to accept global technical settings for the VDX system, as opposed to what might have been preferred locally. Since the inception of the shared system, consortium members are now moving forward with common archiving, report generation, invoicing, and loan policies. 
Ryerson Library's experience illustrates areas where individual sites have demonstrated adaptability and flexibility. For example, all OCUL sites now share a system-wide request form. Ryerson is one of the few universities in Ontario without multiple campuses. Therefore Ryerson does not need a field in the end-user request form for a selection of locations for pick-up of ILL materials. Ryerson does not charge its users for ILL service and therefore does not want a display of charges. Further, Ryerson users are not used to seeing the terminology "University ID” as it is used on the RACER registration form. After registering Ryerson end users frequently forget what information is used to log into the RACER system. Where these features are OCULwide, textual modifications or accommodations could not be made to specifically address Ryerson local needs. Fortunately, through education, users have learnt to ignore additional fields and/or understand what is relevant and how it should be applied within their local context. Also, there were times, especially at the start of the project, that Ryerson's staff felt they had more autonomy in the "AVISO era”. Prior to the 2008 addition of JASPER reporting functionality they also felt they had less control of the desired statistical output or generation of invoices. Nevertheless, Ryerson staff members were flexible enough to recognize there is always a tradeoff in the transition from one system to another, and that compromises for the common good eventually pay off.

\section{Key factor - leadership}

Key factors were: core guidance and representation from all participants.

\section{Core guidance}

One might ask how the people acting as project and local leader(s) obtained the commitment, and sustain the motivation of such a large group of individuals? When looking at the causes of IT failure, Karl Schneider has determined that non-technical factors, rather than the technical skills of project managers, are key to ensuring project success. The Coverdale Organization Study found that communication, expectation and time management failings concerning stakeholders and project team members, rather than lack of technical skills or technical issues were identified as major "project killers" (Schneider, 2002). Therefore, another important attribute to shared success in collaborative partnerships is good leadership and full support and engagement of people in leadership roles. Participants in the Coverdale Organization Study identified the involvement and support of senior management as vital to any IT project's success (Schneider, 2002). The RACER project was given a firm foundation because the Library Directors fully committed to and supported the RACER initiative. The Library Directors had the foresight to recognize the potential of the venture. Further, this buy-in from the top-level meant that ILL Managers were assured support when acting as leaders within their units.

\section{Representation from all participants}

At the time OCUL began discussing the possibility of implementing a province-wide ILL system, the University of Toronto and the Tri-University Group (consisting of University of Guelph, Waterloo University, and Wilfrid Laurier University) were well advanced in initial reviewing of ILL software. They demonstrated cooperative spirit and leadership by sharing this 
information with all the member libraries and inviting the other OCUL members to participate in evaluating ILL products.

Further, over the course of the project, numerous volunteers from member institutions have served on teams that have assisted, advised or overseen the activities of the RACER Implementation Team. These include:

- $\quad$ Standards Sub-Group.

- Training Sub-Group.

- Reports Sub-Group.

- French Language Sub-Group.

- OCUL ILL Task Group.

- $\quad$ OII (Ontario Information Structure) Project Management Team.

- $\quad$ End User Instruction Working Group.

- Web Site Working Group.

- Collection Development Working Group.

- Key Implementation Team.

- External Locations Sub-Group.

- $\quad$ Self Patron Registration Implementation Testing Team.

Ryerson officially participates in various core guidance groups and assisted with beta testing.

\section{Key factor - financial support}

OCUL participants, in conjunction with the OCUL ILL Task Group, examined a range of ILL management systems during the evaluation process. VDX was identified as the most suitable, but not the least expensive solution. Government funding obtained from the Ontario Innovation Trust (OIT) allowed OCUL to purchase a consortial license for the VDX product suite, whereas the cost may have been otherwise prohibitive for some of the institutions individually.

When the provincial government funding (via the Ontario Innovation Trust grant) ended in December 2004, the Library Directors agreed to provide funds for the initiative from their libraries' budgets on a shared-cost basis. The cost-sharing model being implemented as part of the sustainability funding for the entire Scholars Portal considers several factors such as: amount of system usage, institution size, fte (full-time equivalent) student numbers, and provides recompense for making high use of services. Further, member universities regularly host meetings and assume the associated staff travel costs and volunteer time - all necessary to advance the operation. Ryerson Library management has strongly supported OCUL's RACER initiatives.

\section{Key factor - technical support}

Ryerson's interlibrary loan staff used AVISO ILL management software before adopting VDX. With the arrival of RACER, interlibrary operations progressed from a standalone batch process system, to a state-of the-art system that made it easier to send and receive messages in real time. 
Cheung's article outlines the differences between Ryerson Library's former ILL management system as it then existed, and the VDX replacement (Cheung and Patrick, 2004).

In the old AVISO environment staff keyed information supplied by end users on paper or rekeyed data submitted via an online form. At that time Ryerson lacked sufficient dedicated technical support staff to use the AVISO software to its fullest potential. In-house expertise did not exist to customize the software to meet Ryerson's specific needs. The inability to network the system meant it could not be accessed by multiple staff users; rather ILL staff had to schedule their time to process requests on a standalone workstation system. Immediate advice on day-today systems issues and emergency coverage was limited. With the then existing technology and programming expertise, basic tasks such as developing an in-house online request form that parsed into the AVISO system were difficult.

The introduction of RACER brought a dramatic change in the level and types of user and system support required locally. Ryerson Library has one of its systems librarians act as RACER systems consultant and trouble-shooter, responsible for providing input on settings that affect Ryerson's interlibrary loan policy and service operations. In addition to managing Ryerson's ILL unit, the Interlibrary Loan librarian functions as the Ryerson "VDX Main Contact”. As a VDX Main Contact this individual acts as liaison for communications between the Ryerson ILL unit and the Scholars Portal Operations Team. She acts as Ryerson's representative at ILL business meetings and on working groups and committees as required. During the implementation, these two individuals worked closely with members of the OCUL RACER Implementation Team, which included a user-support librarian to answer workflow questions, a database administrator to handle hardware and system issues, a programmer to create OCUL statistical reports and a project manager. This centralized team regularly provided system information, training, and workflow and statistical reports. Open communication within the consortium was encouraged in order to facilitate easy and rapid flow of shared information on technical, policy and other issues. Sites continually propose and volunteer to test modifications to existing functionality, new features, and amended workflows.

\section{Key factor - cooperation}

\section{Equal access to shared knowledge}

As detailed earlier, the project started on a firm foundation of openness and information sharing because the OCUL sites who were involved in early Requests for Proposal (RFPs) and assessments willingly shared their evaluative information with the entire consortium. Other nonmember organizations such as SOLS (the Southern Ontario Library Service that provides services to public libraries and also uses VDX) readily shared information about their own emerging projects. This resulted in open sharing of information and supported well-informed decisions. Throughout the project this principle has been fostered. As a result the process of sharing information is now deeply entrenched, both formally and informally. The OCUL VDX staff support web site is a first point of access to specific details on RACER, project information, news and ongoing support. 
Project groups formed by selecting members from across OCUL bring together valuable and varied experience and knowledge. The result is better informed decisions and a more in-depth information base. The new knowledge acquired is of benefit to the individual and to the participating institutions. Not only are hard technical skills and knowledge acquired but also the ability to develop the softer group skills such as negotiation, understanding the importance of compromise and accommodation, and networking. Working with the RACER Implementation Team and contributing to the implementation newsletter gave many staff the opportunity to participate on OCUL working groups and engage in professional development activities that they may not have otherwise been afforded.

\section{Key factor - staff commitment}

A committed staff is indispensable for project success. In the case of Ryerson Library interlibrary loan staff members deserve full credit for their efforts. Becoming comfortable with RACER involved a considerable learning curve. In the pre-implementation stage, staff members were required to test VDX under simulated conditions, first with each other in the Ryerson Library and then, with interlibrary loan staff in OCUL member libraries. The switch to the new system was not easy. To further complicate matters, the timing of RACER's launch coincided with major building renovations. To add to this, Ryerson library technicians also work at the Reference Desk so a fine balance has to be maintained between competing work priorities. This was a stressful period for staff who were asked to make concessions, be flexible, and adapt to change within Ryerson while also participating in the on-going dialogue with our OCUL partners. Whether it be working within the OCUL context on the RACER implementation and development of shared system settings and policies or addressing local workflow challenges, staff attitudes mirror those observed by Hightower and Soete where they suggest that "a customer focus is critical as projects are developed. In a profession like librarianship, where motivation is likely to be of the self-actualizing variety, a strongly held sense of benefit to customers will promote effective collaboration” (Hightower and Soete, 1995).

Once RACER went into production frequent troubleshooting meetings were held. These could involve staffing and human resource matters or policy, procedural, or technical issues. At times chaos seemed imminent. Staff needed to adapt to changes in workflow and workload, and to a new division of labour. For a period of time Ryerson ran multiple interlibrary loan management systems phasing out the old AVISO whilst running the new VDX. Some VDX functions were not yet operating efficiently - for example it was not possible to print address labels and VDX could not "talk to" OCLC ILL ME (MicroEnhancer)/Passport the third system, which Ryerson was using to conduct international interlibrary loan. Even more recent applications such as the installation of link-resolver software (SFX) in 2007 did not arrive problem-free. However, interlibrary loan and reference staff members continued to exercise patience while the issues were addressed.

\section{Key factor - communication}

Communication was one of the key reasons for success. The RACER Implementation Team had numerous methods of communicating with, and obtaining feedback from, individuals and groups. Explanations of why specific configuration decisions were made, status updates and 
development plans were all made available. Initially Ryerson and OCUL ILL staff members were intimidated by the volume and complexity of the information required to understand the entire project. To overcome this, the RACER Implementation Team broke the information into manageable categories. These were communicated through listservs e-mail, bulletins, periodic OCUL updates, primers, manuals, surveys, newsletters, the RACER staff support web site, and more recently the Scholars Portal Operations Team's web site and wiki. Frequent communications using a variety of well established methods allows local ILL staff to prioritize and act on time-sensitive information. They can archive and retrieve information at their convenience and stay abreast of current developments. It also ensures that the rationale for decisions and prioritizations made by the centralized OCUL Team and/or the various associated OCUL working groups and committees are communicated directly to the people who will be affected by them.

\section{Key factor - staff- and end-user-centered focus}

\section{(Ongoing feedback for development)}

As a result of the trust developed through the initial collaborative process, there exists a culture of open communication that encourages feedback. This feedback supplies the centralized team with the information it needs to adjust its methods or strategic plan. This process allows leaders to identify areas for improvement, evaluate a wide range of suggestions, establish priorities, and take appropriate action. To facilitate this feedback from individuals and institutions, Scholars Portal Operations Team provides varied avenues for interlibrary loan staff concerns to be addressed and for other stakeholders in the consortium to stay abreast of developments. These range from direct suggestions via email, and wiki contribution, to the more formal sharing of ideas and tabling of concerns.

At the local level, it is not unusual for a Ryerson ILL staff member to take a suggestion to the Main Contact who can then pass it on to the centralized OCUL Team. All submissions are evaluated by either a working group or the centralized team as appropriate. Feasible ideas are added to the planning schedule. In many cases these local suggestions then become the basis for global system configuration or are shared and/or adapted by the consortium members at large. One example of this is the pre-launch tool kit developed by contributing OCUL libraries. The tool kit contains a wide range of in-house marketing tools such as bookmarks and pamphlets. Another more recent example of an individual contribution is a shipping container designed by an interlibrary loan staff member from Waterloo University. The container was adapted to solve a so-called "procedural pothole" - the cumbersome mailing of microfilm - and is now being used by some member libraries.

OCUL staff suggestions have also influenced the development of new iterations of the VDX software. Ideas suggested to improve workflow or the end user interface are often submitted as product enhancements to OCLC and then, if selected by the larger North American VDX Software Users Group, are included in future releases of the product. In this way, feedback, even if it should be from frustrated or confused users or from staff, can have a positive impact on policies and procedures and can eventually result in greater staff and user satisfaction. This process takes time but the democratic nature ensures: 
- the exploration of possibilities;

- all types of users' commitment to the process and the product increases;

- input is gathered from a broad base of perspective and experience; and

- ILL practitioners have the opportunity to suggest innovations in light of current and future trends.

Providing good service and building the local Ryerson ILL end user-base remained a priority throughout the RACER implementation, and staff were very concerned that the quality of service not be compromised. As the new system was being phased in, end users were made aware of the progress being made. Opportunities to submit feedback were provided and end users were encouraged to give input. Many end users felt free to comment and make suggestions. Many welcomed the new, while others clung to the familiarity of the old. Ryerson Library staff and end users saw immediate benefits. Turnaround time decreased; demand for materials increased (Figures 2 and 3). As everyone became more comfortable with the continually improving system, the number of requests rose dramatically. Ryerson Library had to be nimble enough to make staffing adjustments to manage the changing workload. Continual modifications to VDX (i.e. the implementation of auto-mediated requesting) have helped staff at OCUL sites dispense more quickly with borrowing requests. Auto-mediation (direct requesting) has now been implemented at Ryerson and staff look forward to having more time to work on activities that support the strategic goals of the university. These include providing more efficient service to targeted groups like graduate students (who traditionally place requests for more difficult items to locate) and distance education students who have special needs.

At a 2007 post-implementation OCUL ILL Managers' business meeting anecdotal accounts from other sites mirrored the increase in demand experienced at Ryerson throughout 2003-2006.

Statistics suggest that OCUL's overall ILL activity tends to parallel the trends observed by Anne Beaubien in the 2007 ARL White Paper on Interlibrary Loans. Beaubien has written that data collected by the US Department of Education and the Institute of Education Sciences indicates that statistics for academic libraries in the US show that returnables went up 26 percent between 1998-2004 while requests for non-returnables went down 4 percent during the same period. She attributes this pattern to increased licensing of electronic journals, the proliferation of internet discovery tools, academic libraries making ILL requesting easier for users, and the adoption of unmediated ILL (Beaubien, 2007). In the case of OCUL, the arrival of RACER also heightened the awareness and use of ILL services. Even with the decline in 2007 in overall requesting the trend regarding more loan requests than copy requests is consistent.

However, Figures 4 and 5 suggest that the number of OCUL requests filled is decreasing since 2007. The shift in the number of loan requests is much less dramatic than the drop in the number of journal requests. There is a divergence in the pattern at Ryerson as of 2007, whereby the number of journal requests is outpacing the number of loan requests. This may not be a new OCUL trend but rather may be specific to Ryerson's current local circumstances. Early analysis suggests that this rise in journal requests reflects:

- a rise in the university's number of graduate programs;

- the implementation of link-resolver software that enabled students to easily request articles directly from within journal databases; and 
- a recent influx of newly purchased books and the adoption of a book approval plan.

\section{Key factor - training}

Training is crucial in any implementation of new software, particularly in a complex consortial environment. As a matter of principle, OCUL recognizes that "effective integration of systems and services into the activities of the individual OCUL institutions requires a significant amount of training, support and communications” (Scholars Portal, 2006). Information needs to be disseminated in various forms and at several different audience levels. In the case of RACER, ILL Managers require in-depth knowledge in order to troubleshoot and assist with configuration decisions. ILL staff need daily tasks clearly outlined. Staff working in public service are looking for materials that succinctly describe the service from an instructional point of view. End users more often prefer glitzy online tutorials or help tools accessible at point of use.

Once the initial decision to proceed with a centralized system was adopted, the ILL Task Group hired people with the needed training expertise, who then recruited dedicated OCUL volunteers to assist with the training. Members of the RACER Implementation Team developed the training syllabus and customized the manuals provided by the vendor with the assistance of the Key Implementation Team and the Training Sub Group (both made up of OCUL ILL Managers and IT staff). The Training Sub Group adopted a "train the trainers" approach. As much as possible, the trainers travelled to the member institutions and trained ILL staff members in a simulated production environment where ILL staff could practice without fear of making errors. This initial training was followed by group training closer to the implementation date at several "host" institutions, including Ryerson, which was part of the first group to implement. The local trainers who attended group training then returned to their institutions and held training for their remaining staff.

The introductory training has been continuously supplemented by numerous support tools (context-sensitive help in RACER, manuals, primers, step-by-step guides), which are made available on the VDX staff-support website. Like the other OCUL locations, Ryerson library staff members now receive "maintenance" training via the OCUL VDX Users and ILL group listservs. This is necessary because of regular product development software upgrades, and the implementation of new features and enhancements. In addition, there is a sharing among Ryerson staff, indeed among OCUL Resource Sharing Staff, of information learned. Scholars Portal's strategic development plan also call for the adoption of new approaches to training that incorporates new technology. OCUL has established a conferencing system that facilitates training via Webinar for OCUL staff, library staff and end users.

\section{Key factor - evaluation (periodic assessment)}

Examples of the difficulty in accurately defining "success" are prevalent in project management literature (Yourdon, 2001). Technical change does not occur in isolation and evaluation of IT projects can often be coloured by concurrent organizational change within the institution. Defining success within a consortial environment or on a collaborative project is even more challenging. What constitutes success from the implementation team's point of view can be very different from local perceptions, where success depends on more than evaluation of the 
performance of the new ILL product and having met established timelines, budget, service levels, and reporting requirements. While the centralized teams' view of the project has a clearly defined scope and parameters, within the context of an individual OCUL ILL unit, the perceptions of success can frequently include local factors that fall outside of what can be measured or beyond what is in anyway influenced by the activities of the RACER Implementation Team. These might include:

- $\quad$ staffing levels;

- $\quad$ working conditions;

- $\quad$ staff competencies;

- local goals and objectives associated with the introduction of the new system (i.e. adopting a paperless workflow);

- provisions for cross-training;

- number of and condition of local hardware (e.g. scanners, PCs, printers); and

- variations in performance caused by local network and Internet connections etc.... .

One reason that the project has been seen as a success is a judicious amount of expectation management. At some point almost everyone will fall into the trap of expecting a new system to solve all the old problems. As soon as it was decided that OCUL would adopt a staged implementation approach, where sites and features would be implemented at intervals, it became obvious that the first roll-out would not deliver the full and completed solution. This message was repeatedly stressed in initial communications and continues to be relevant within the maintenance, upgrade and evaluation stage.

OCUL is continuing to move forward with additional features and assessment activities. System wide and local statistics are invaluable tools. Reports are being developed that can provide performance measures such as turnaround time. At Ryerson, analysis of RACER statistics has helped to identify and inform several developments:

- human resources and staffing, the hiring of an additional ILL technician and staff crosstraining;

- $\quad$ resource forecasting, analyzing requesting patterns by user type and by department in order to estimate the level of collection, instructional and program support needed;

- $\quad$ areas where end-user training may be needed; and

- collection development, to make user driven and informed purchasing decisions.

Within a year of the majority of the implementation there was a follow-up consultation with the vendor and an onsite assessment visit from the OCLC VDX Product Analyst. Recognizing the importance of user satisfaction (both library staff and end user), there has also been an OCUL wide call for product enhancement and policy suggestions. End user evaluation will be done by the Scholars Portal Public Services Advisory Group, which facilitates user-driven evaluation of services. Further, the RACER service will be one of the components evaluated by members of the Scholars Portal User Panel once it is formed in the upcoming year. Though the initial phase of the project is now completed, regular evaluation will be ongoing. 


\section{Conclusion}

The undertaking of this ILL project has advanced OCUL's objective to deliver "collaborative and innovative library services that are critical to the success of Ontario's universities" (Ontario Council of University Libraries, 2007). The OCUL VDX implementation has achieved the originally expected economies of scale, service performance improvements and reduction in localized maintenance and system support. This has been achieved through transparency, communications - at times busy ILL staff might say too much communication - and goodwill. However, there have also been several unforeseen benefits such as the formulation and standardization of the OCUL ILL policies, and the development of Canada-wide consortial reciprocal agreements. At the operational level, staff have had to adjust their management styles and develop confidence not only in their individual skills but also in cooperative thinking, reliance on centralized support, and in the overall system. Over and over again they have displayed creativity, patience, willingness to change, flexibility, and risk-taking. Throughout the project the objectives have been clearly identified, and for the most part, enthusiastically adopted by consortium members. This has lead to a spirit of cooperation that has prevailed past the implementation phase. Recognizing that ILL is a service that is in transition, staff now look at business transformation and ways to identify, share and adopt best working practices.

It has been noted that "a critical question for libraries, as they move toward greater interdependence, is whether a consortium can behave like a learning organization, gaining knowledge from both success and failure, and modifying behaviour accordingly” (Hightower and Soete, 1995). The experience of overcoming implementation obstacles and recognizing the pivotal nature of the factors discussed above has created a foundation for the flexibility OCUL will need as member libraries face future challenges. 


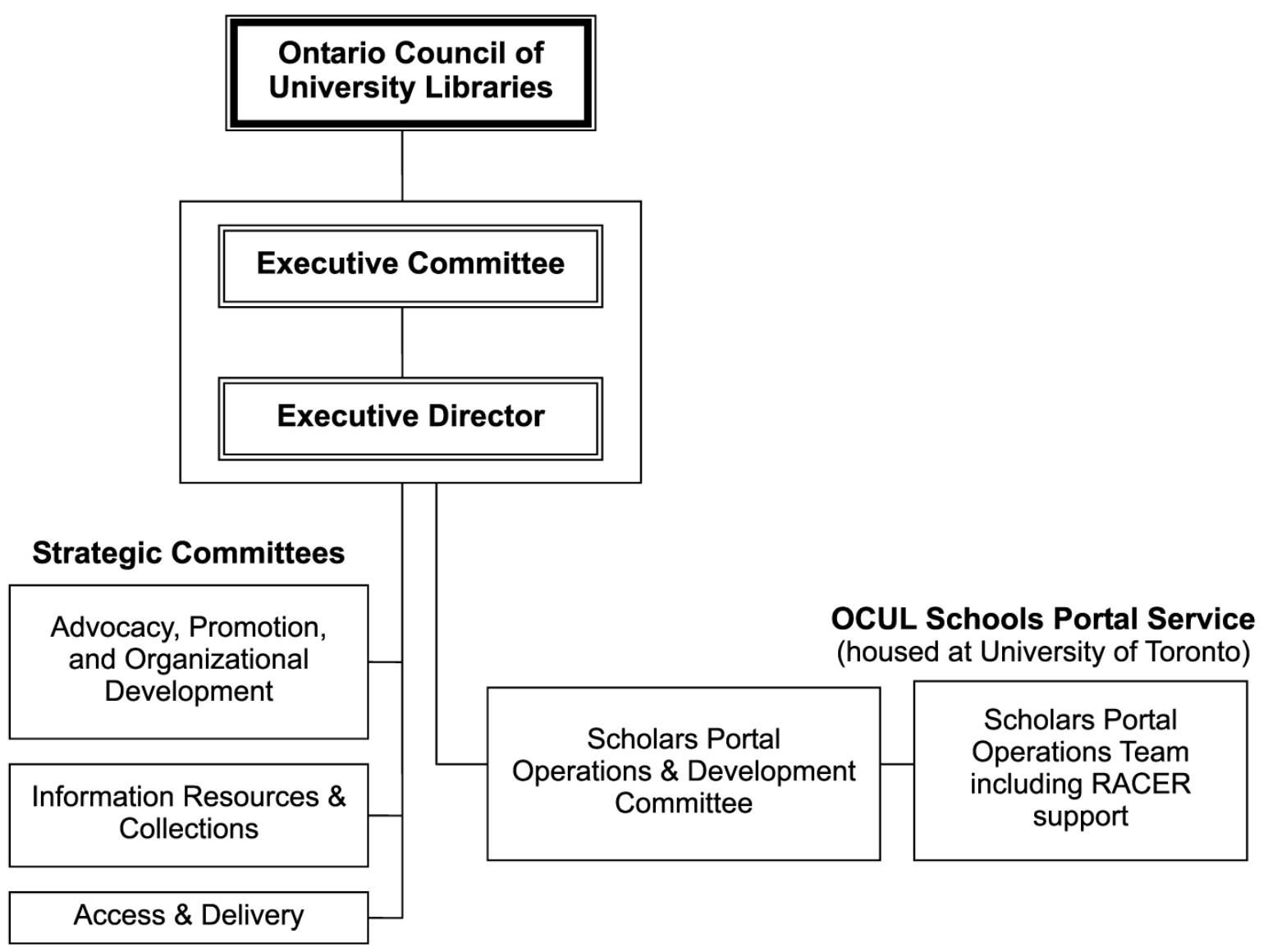

Note: OCUL's Scholars Portal Service delivers consortial licensing and purchases, electronic resources, and services such as VDX ILL management, SFX and Verde software. Members of the RACER Implementation Team are not part of the larger overall Scholars Portal Operations Team Source: Ontario Council of University Libraries. "About OCUL" Copyright 2007 Figure 1Organization chart of the Ontario Council of University Libraries (OCUL) 


\section{Ryerson VDX Borrowing Requests (Total Requests Filled)}

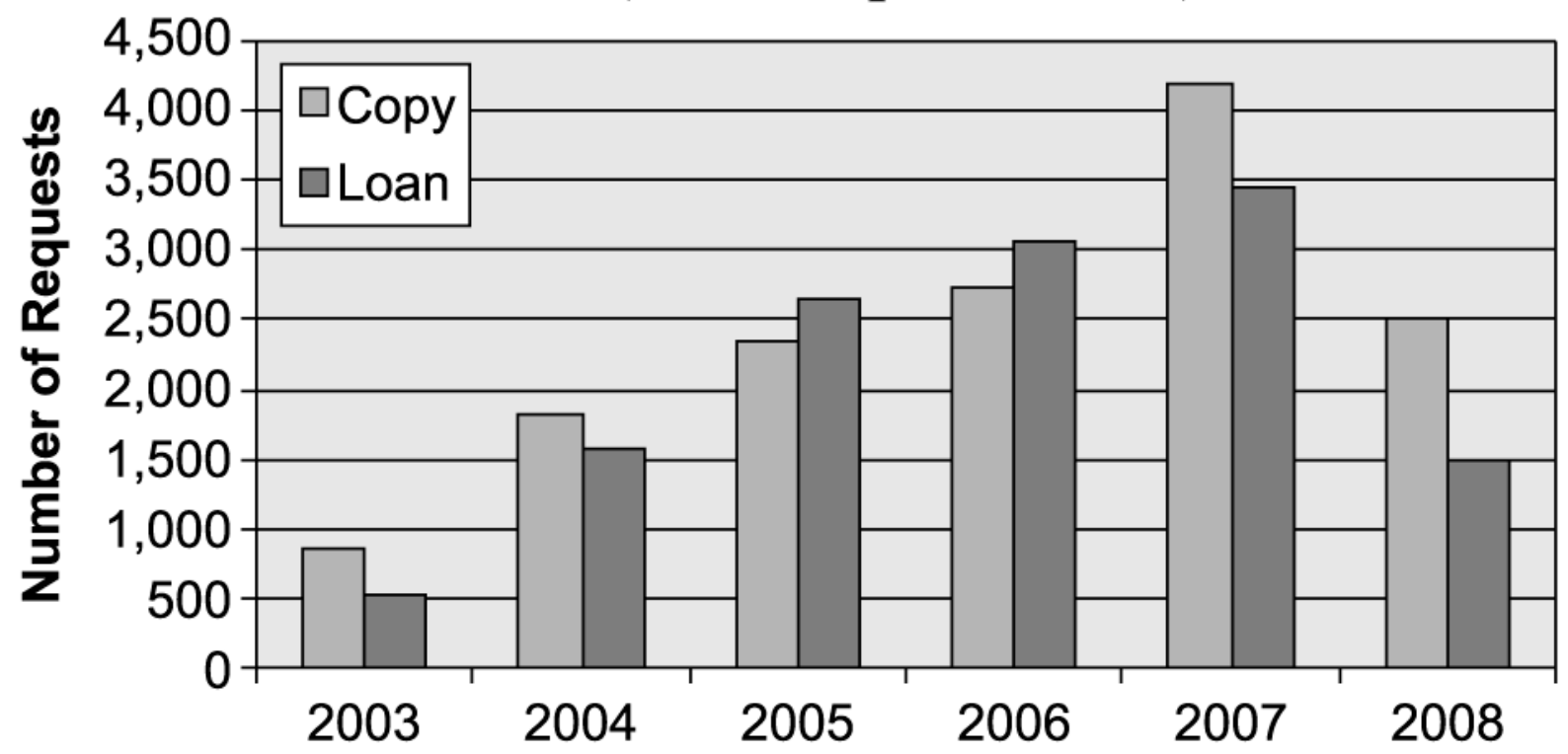

Note: Figures reflect successfully filled requests, note that 2003 is from mid-June forward and 2008 ends July 31st

Figure 2Number of Ryerson VDX ILL borrowing requests filled between June 2003-July 2008 


\section{Ryerson VDX Lending Requests \\ (Total Requests Filled*)}

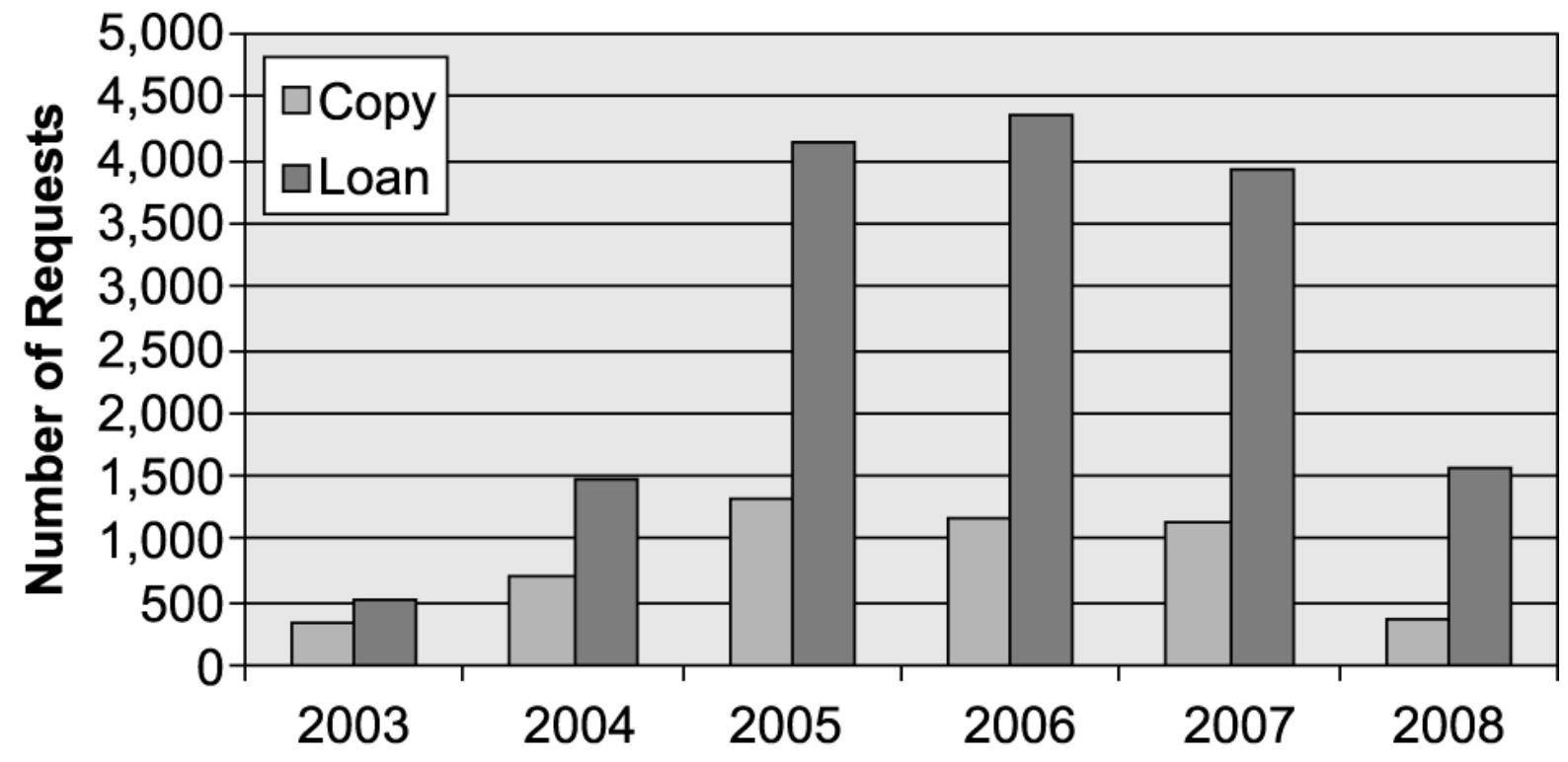

Note: Figures reflect successfully filled requests, note that 2003 is from mid-June forward and 2008 ends July 31st. *Does not include requests received and filled via OCLC

Figure 3Number of Ryerson VDX ILL lending requests filled between June 2003-July 2008 


\section{OCUL VDX Borrowing Requests}

(Total Filled)

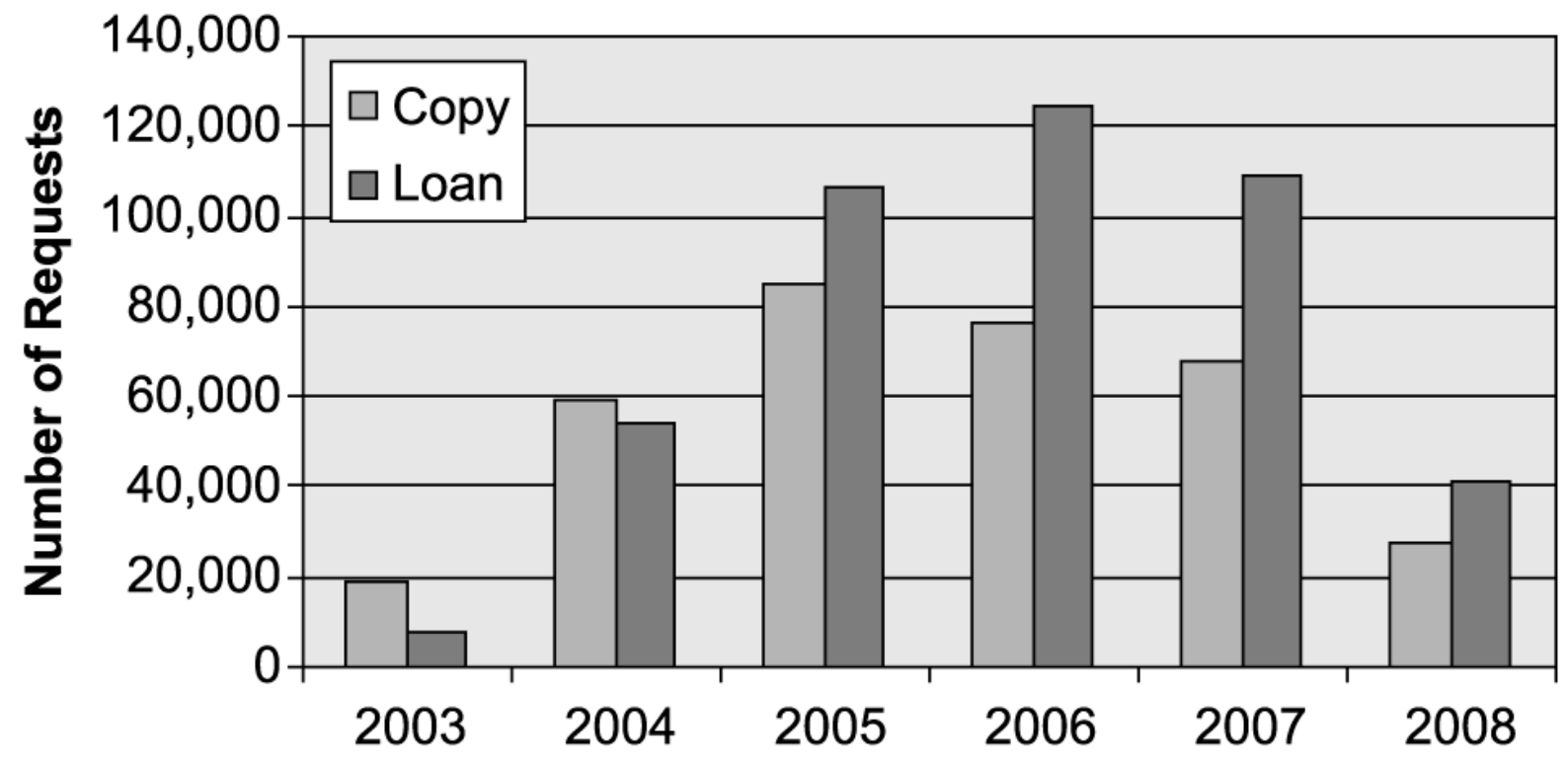

Note: Due to the phased-in implementation approach earlier years' numbers only include half of the OCUL libraries (volume overall)

Figure 4Number of OCUL VDX ILL borrowing requests filled between June 2003-May 2008 


\section{OCUL VDX Lending Requests \\ (Total Filled)}

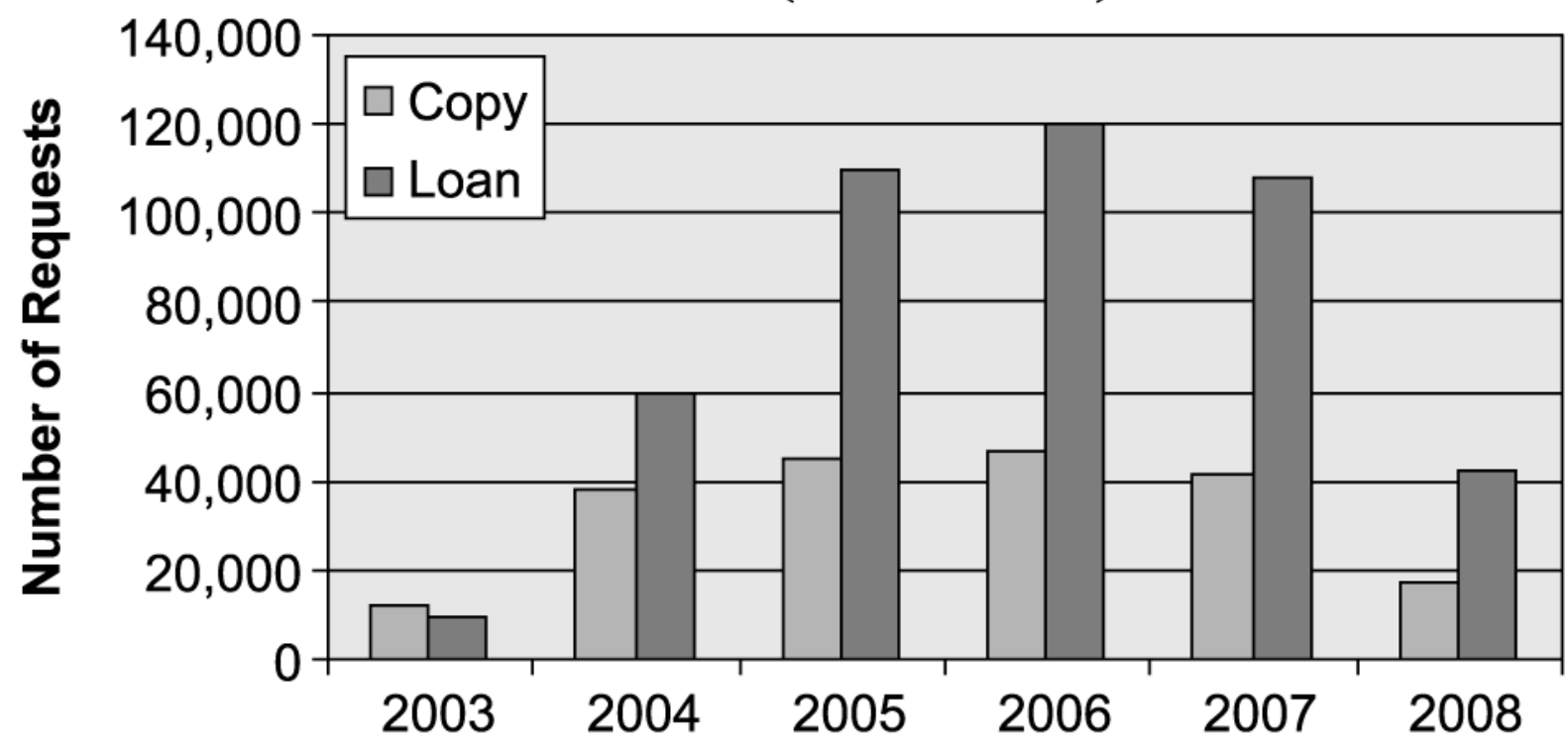

Note: Due to the phased-in implementation approach earlier years' numbers only include half of the OCUL libraries (volume overall)

Figure 5Number of OCUL ILL lending requests filled between June 2003-May 2008

\section{References}

Beaubien, A.K. (2007), ARL White Paper on Interlibrary Loan, June 2007-last update, Homepage of Association of Research Libraries, online, available at:

www.arl.org/bm doc/ARL_white_paper_ILL_june07.pdf (accessed 24 July 2008), .

Best's Review (2006), "Avoiding failure", Best's Review, Vol. 107 No.3, pp.70.

Cheung, O., Patrick, S. (2004), "Unmediated is the message: enhancements to traditional interlibrary loan in a Canadian university", Interlending \& Document Supply, Vol. 32 No.3, pp.152-8.

Finney, R. (2003), Successful Project Team Management, 10 May - last update, Homepage of The itmWEB Site ${ }^{\mathrm{TM}}$, online, available at: www.itmweb.com/f051003.htm (accessed 24 July 2008).

Hightower, C., Soete, G. (1995), "The consortium as learning organization: 12 steps to success in collaborative collections projects", The Journal of Academic Librarianship, Vol. 21 No.2, pp.8791. 
Ontario Council of University Libraries (2007), “About OCUL”, Homepage of Ontario Council of University Libraries, online, available at: www.ocul.on.ca/view.php?id=1069 (accessed 24 July 2008).

Schneider, K. (2002), "Non-technical factors are key to ensuring project success", Computer Weekly, pp.4.

Scholars Portal (2006), “Setting directions for 2006/07 and beyond”, November 2006-last update, available at: www.scholarsportal.info/vdx/support/2006_SP_Plan_May06.pdf (accessed 25 July 2008).

Yourdon, E. (2001), "Spelling success", Computerworld, Vol. 35 No.8, pp.39.

\section{Further Reading}

Cheung, O., Fraser, L. (2007), “The perfect match: convergence of technology and resource sharing”, Proceedings of the 2007 World Library and Information Congress: 73rd IFLA General Congress and Council, available at: www.ifla.org/IV/ifla73/papers/096-Fraser_Cheung-en.pdf (accessed 25 July 2008).

\section{Appendix}

ISO: ISO, International Organization for Standardization, is a network of the national standards institutes of 157 countries, on the basis of one member per country, with a Central Secretariat in Geneva, Switzerland, that coordinates the system. They issue technical standards for various industries, including libraries: www.iso.com/

Link Resolver: A link-resolver enables end users to navigate from citations in databases to full text content in other sources. SFX is a link-resolver developed by the company Ex Libris (www.exlibrisgroup.com/sfx.htm) using the OpenURL standard for interoperability between information resources. It transfers citation information seamlessly from borrower library catalogues to electronic resources. The SFX link server appears as a "Get It!" button beside each reference retrieved by an end user's search of Ryerson Library resources (including journal databases). When an end user sees the "Get It!" button in a journal index or article database he/she can click on the button to see a menu that may include varied options, ranging from fulltext viewing, to submitting an ILL request for the item via RACER, if necessary.

RACER: For French language users, RACER (Rapid Access to Collections by Electronic Requesting) is known as RACER - Recherche accélérée pour commander életroniquement rapidement. Guest access available at: http://racer-fr.scholarsportal.info/

\section{About the authors}

Sue McGillivray is the Manager, Collections at CNIB Library, Toronto. She was the Project Manager for the RACER Implementation Team 2004-2007. Sue McGillivray is the corresponding author and can be contacted at: sue.mcgillivray@cnib.ca 
Amy Greenberg is one of the OCUL Scholars Portal User Support Librarians in the Scholars Portal Operations Team. She has been involved with RACER through most of the Implementation phase and launch activities.

Lucina Fraser is the Interlibrary Loans Librarian at Ryerson University Library in Toronto, Canada.

Ophelia Cheung manages AudioVisual and Reserve Services, including E-Reserve at Ryerson University Library, Ryerson University, Toronto. She is also the Librarian who oversees Distance Education Support. Formerly she was the Manager of Interlibrary Loans. 